\title{
Magnetic-Field-Induced Strong Negative Thermal Expansion in
}

\section{$\mathbf{L a}(\mathbf{F e}, \mathbf{A l})_{13}$}

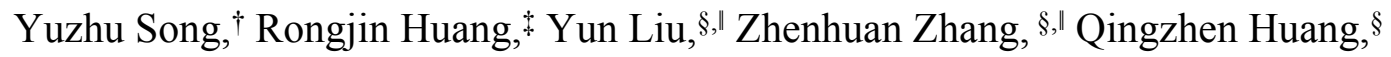

Yong Jiang, ${ }^{\perp}$ Shouguo Wang, ${ }^{\perp}$ Laifeng Li, ${ }^{\ddagger}$ Xianran Xing ${ }^{\dagger}$ and Jun Chen ${ }^{*}, \dagger$

†Beijing Advanced Innovation Center for Materials Genome Engineering, and School of Mathematics and Physics, University of Science and Technology Beijing, Beijing 100083, China

*Key Laboratory of Cryogenics, Technical Institute of Physics and Chemistry, Chinese Academy of Sciences, Beijing 100190, China

\$NIST Center for Neutron Research, National Institute of Standards and Technology, Gaithersburg MD, 20899-6102, USA

"Department of Chemical and Biomolecular Engineering, University of Delaware, Newark, DE 19716, USA

${ }^{\perp}$ School of Materials Science and Engineering, University of Science and Technology Beijing, Beijing 100083, China

* Corresponding author: junchen@ustb.edu.cn 
1. Supplementary figures

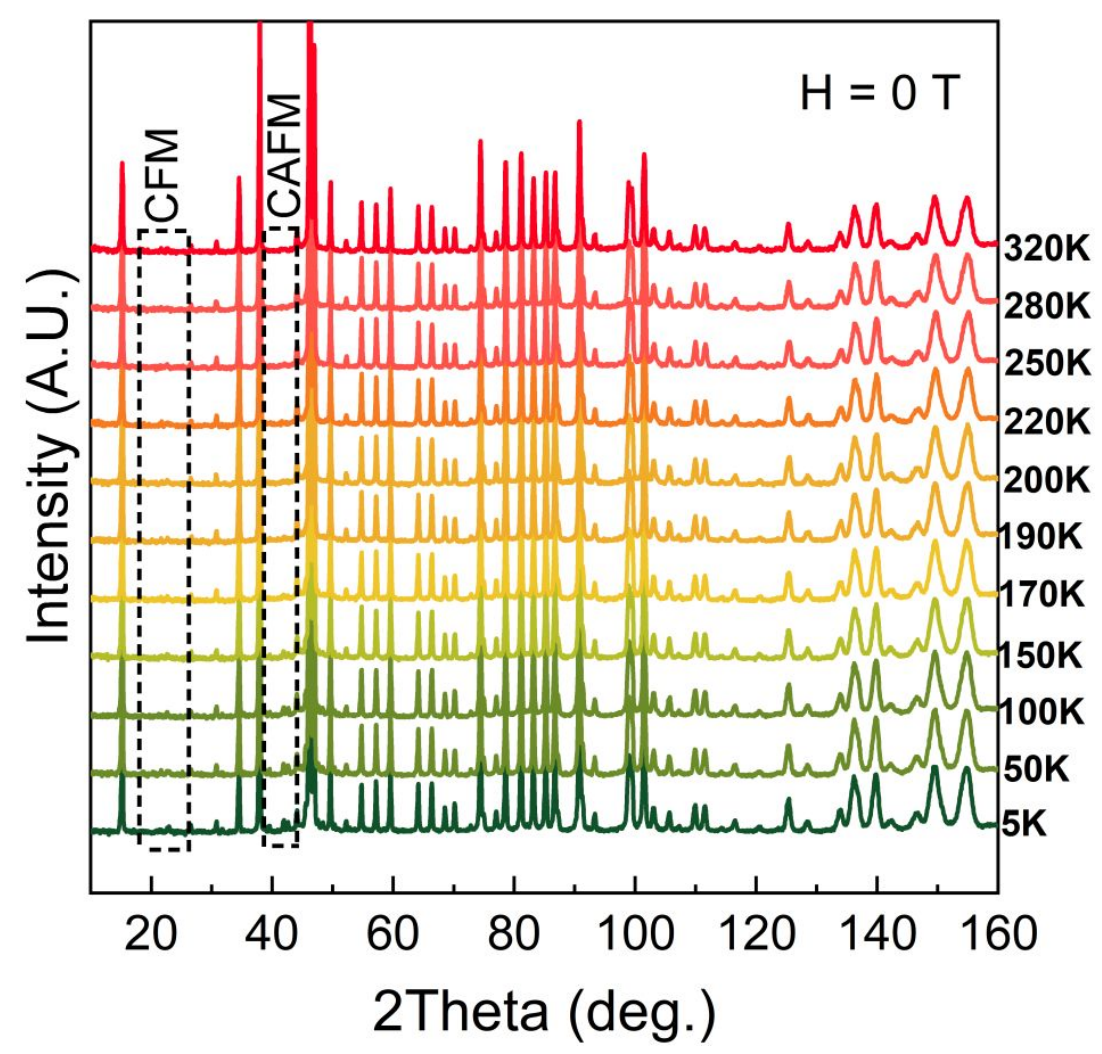

Figure S1. The variable temperature NPD patterns at $H=0 \mathrm{~T}$ for $\mathrm{La}\left(\mathrm{Fe}_{11.5} \mathrm{Al}_{1.5}\right)$. 


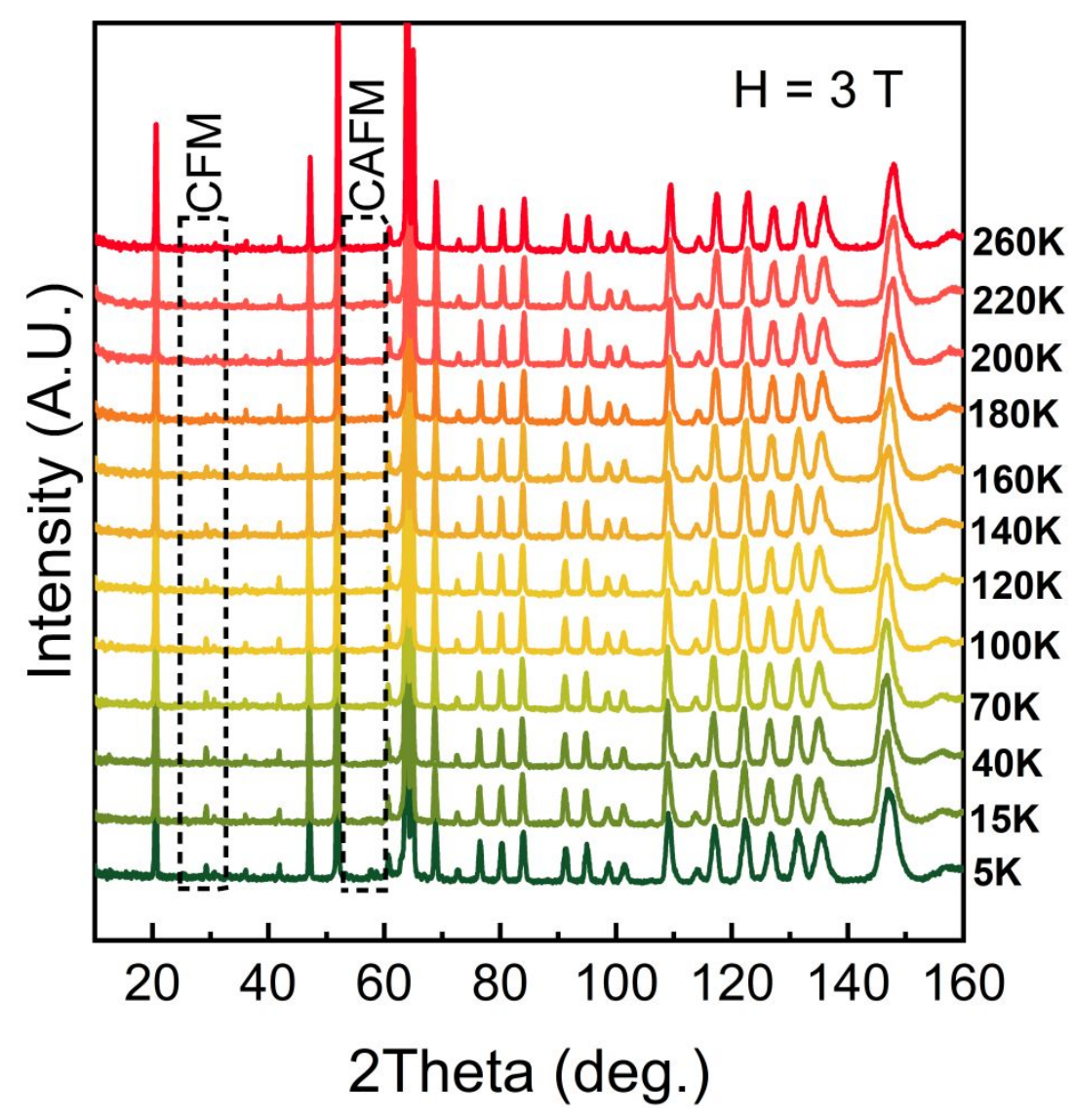

Figure S2. The variable temperature NPD patterns at $H=3 \mathrm{~T}$ for $\mathrm{La}\left(\mathrm{Fe}_{11.5} \mathrm{Al}_{1.5}\right)$.

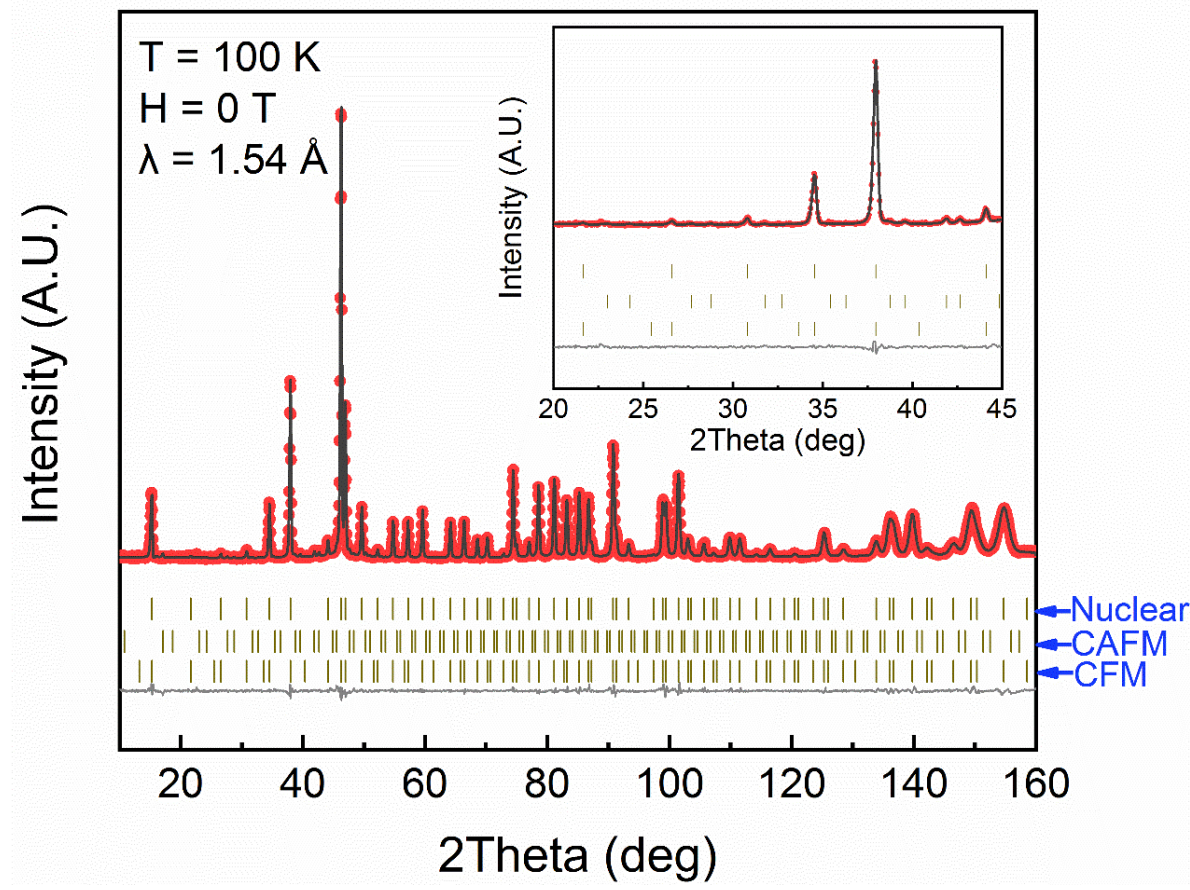

Figure S3. Magnetic structure refinements of NPD patterns with a wavelength of 1.54 $\AA$ for $\mathrm{La}\left(\mathrm{Fe}_{11.5} \mathrm{Al}_{1.5}\right)$ at $T=100 \mathrm{~K}$ and $H=0 \mathrm{~T}$. The inset shows the enlarged region. 


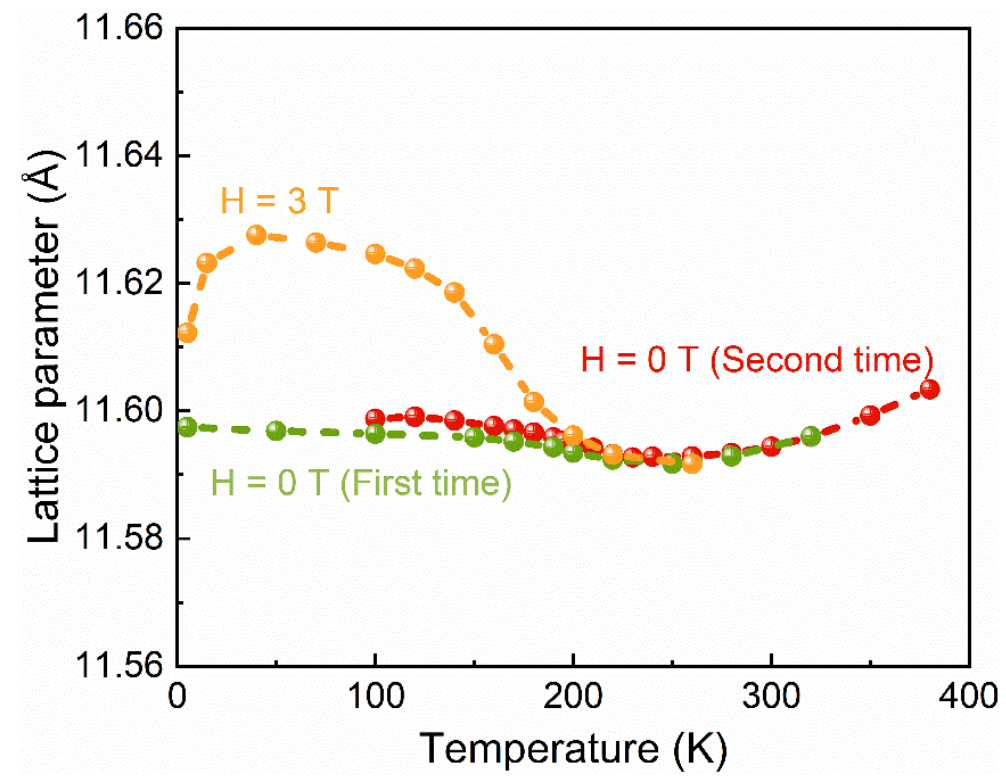

Figure S4. The temperature dependence of lattice parameter $a$ at $\mathrm{H}=0 \mathrm{~T}$ and $3 \mathrm{~T}$, respectively. The thermal expansion at $H=0 \mathrm{~T}$ was measured for the second time after the measurements at $H=0 \mathrm{~T}$ (the first time) and $3 \mathrm{~T}$.

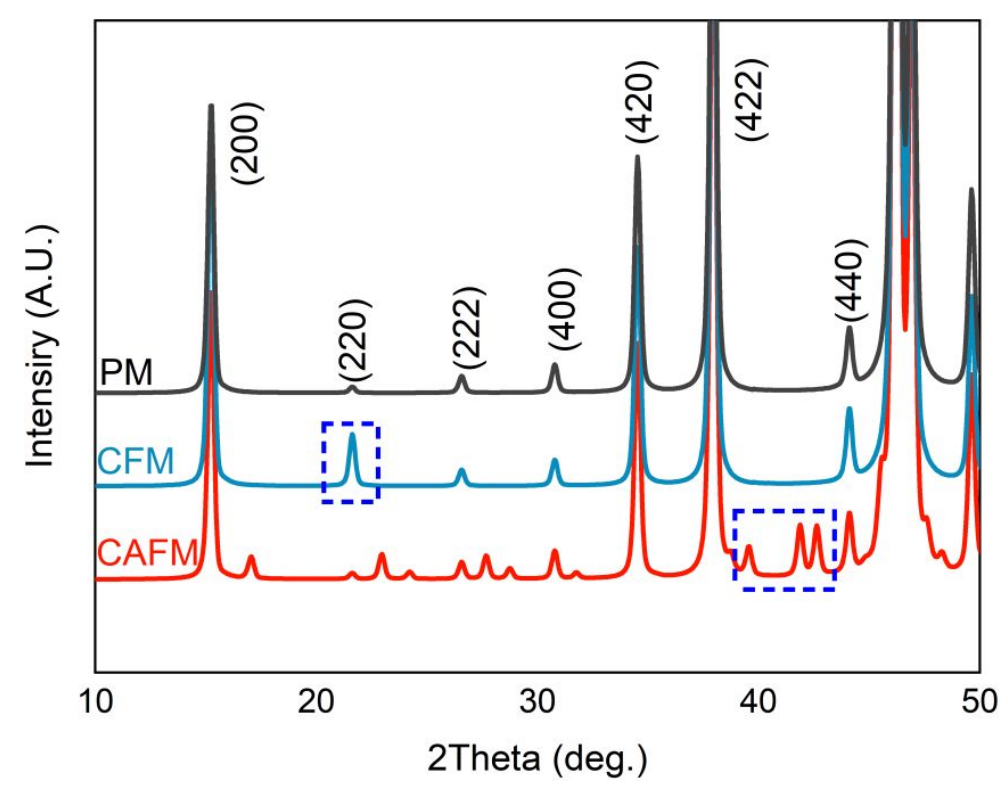

Figure S5. The simulated NPD patterns of $\mathrm{La}(\mathrm{Fe}, \mathrm{Al})_{13}$ with different magnetic structures. The diffraction peaks in the dotted box represent the characteristic peaks of different magnetic structures. 


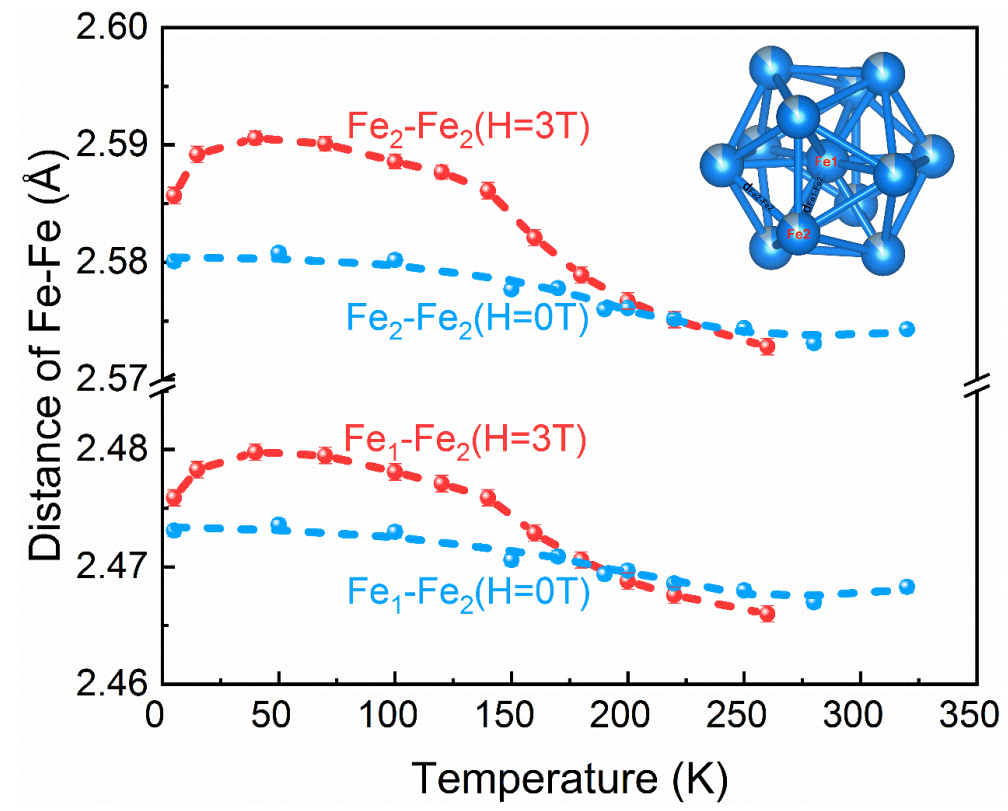

Figure S6. Temperature dependence of $d_{\mathrm{Fe} 1-\mathrm{Fe} 2}$ and $d_{\mathrm{Fe} 2 \mathrm{Fe} 2}$ in icosahedron for $\mathrm{La}\left(\mathrm{Fe}_{11.5} \mathrm{Al}_{1.5}\right)$. The inset shows Fe icosahedron.

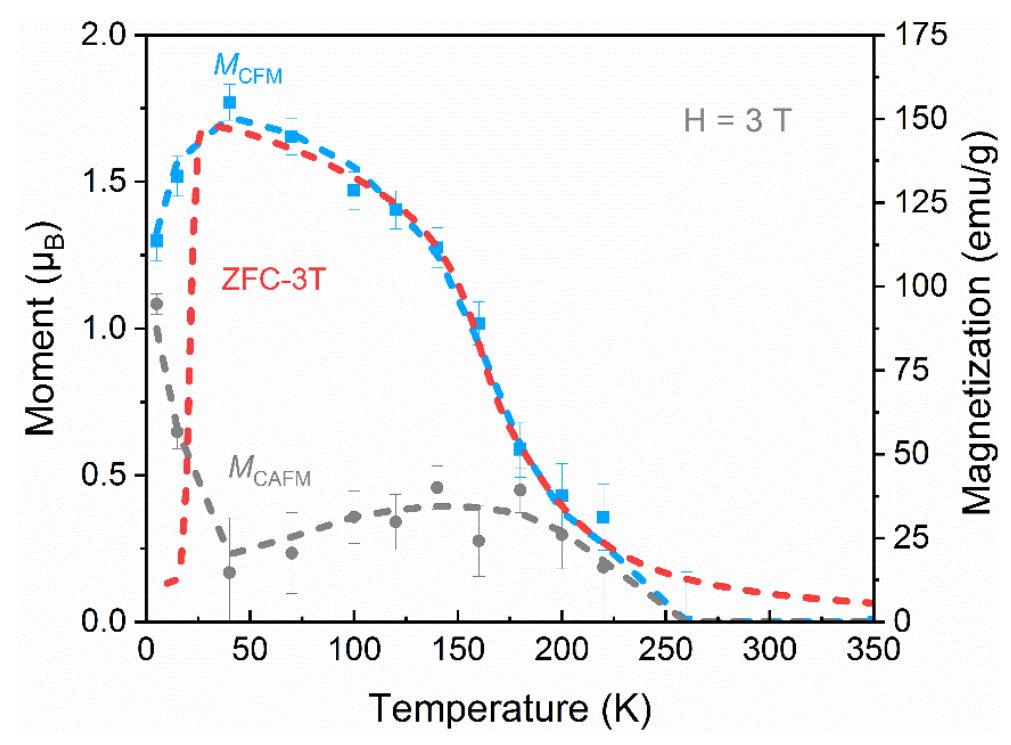

Figure S7. Temperature dependence of $M_{\mathrm{CFM}}, M_{\mathrm{CAFM}}$ and macroscopic magnetization (ZFC) for $\mathrm{La}\left(\mathrm{Fe}_{11.5} \mathrm{Al}_{1.5}\right)$ at $\mathrm{H}=3 \mathrm{~T}$. 


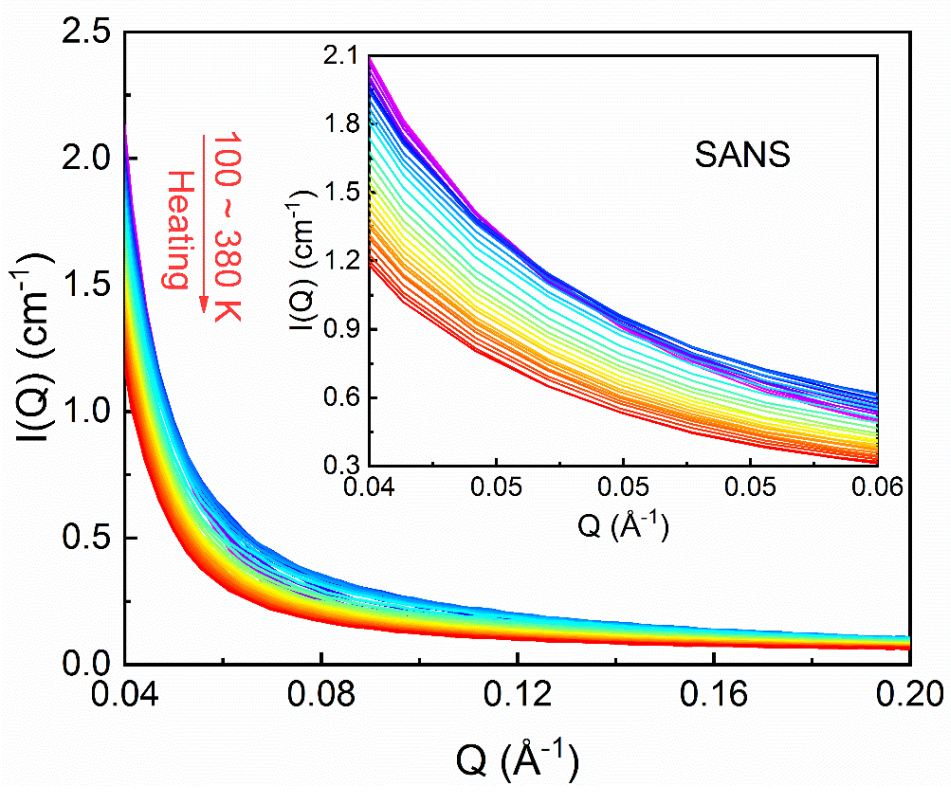

Figure S8. The variable temperature SANS patterns measured between $100 \mathrm{~K}$ and 380 $\mathrm{K}$. The inset shows the enlarged region.

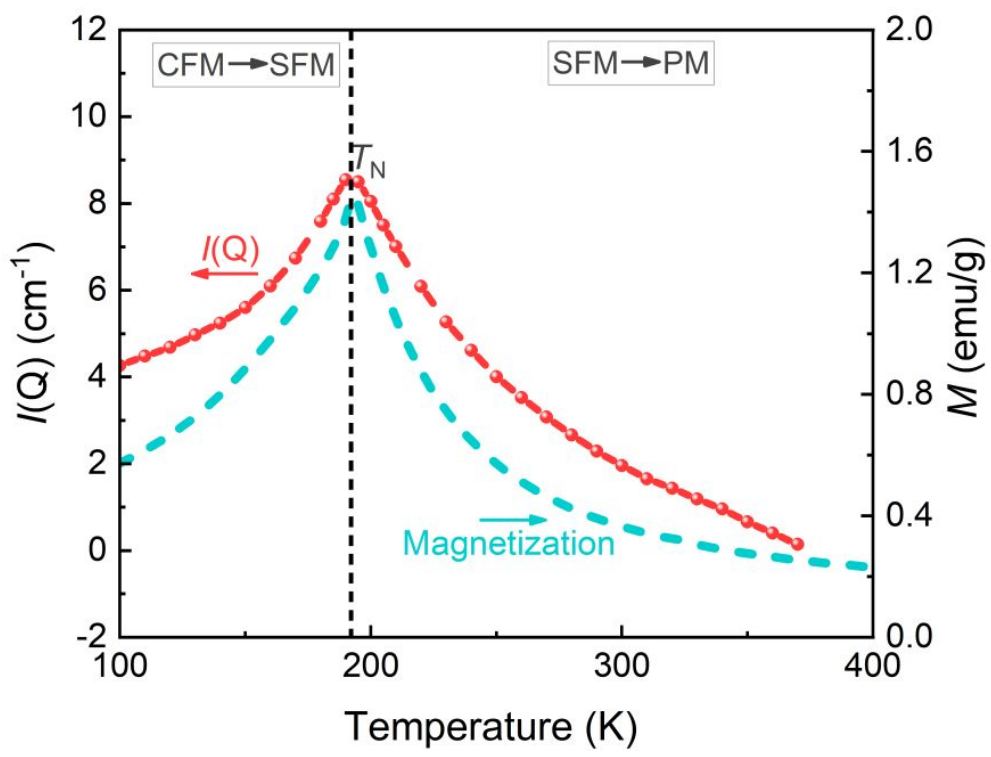

Figure S9. Temperature dependence of the integral intensity of SANS patterns and the magnetization at $H=0.1 \mathrm{~T}$. The CFM-SFM represents the long-range FM component to the short-rang FM order, and the SFM-PM means the short-rang FM order to the paramagnetic transition, respectively. 

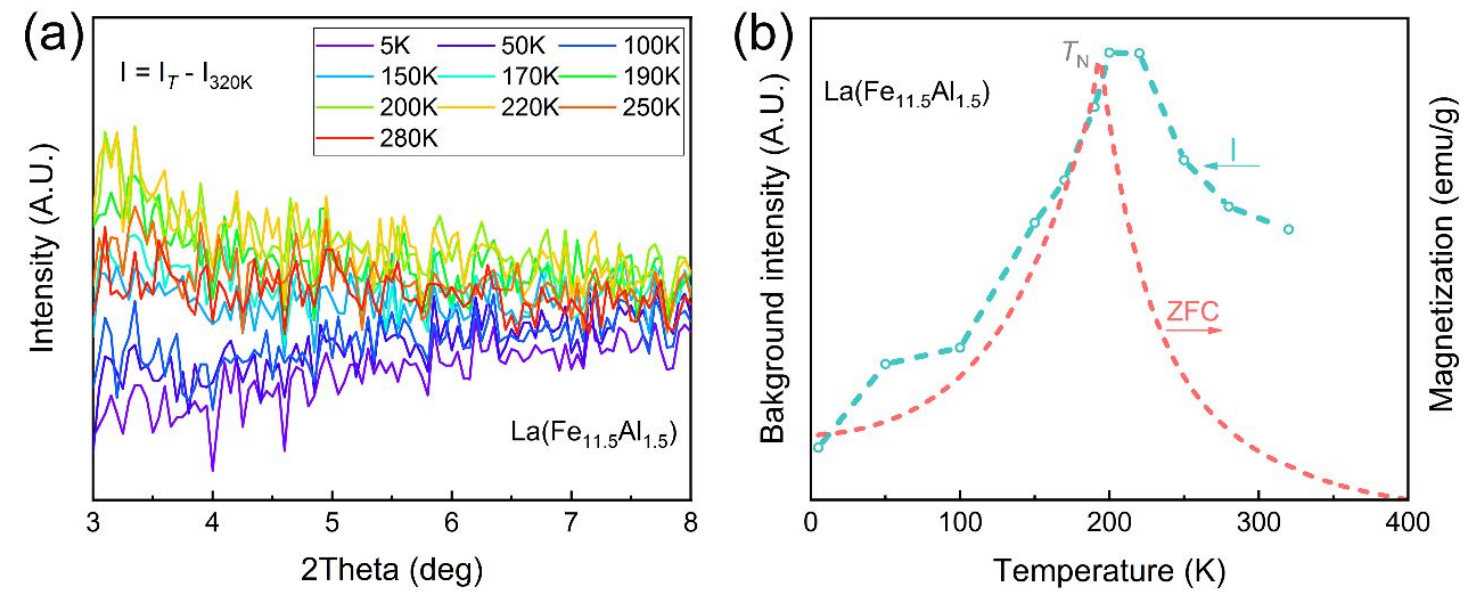

Figure S10. The analysis of short-range magnetic order by neutron powder diffraction at low angles. (a) The NPD patterns with a low angle range (3-8 degree) after the subtraction of high temperature pattern for $\mathrm{LaFe}_{11.5} \mathrm{Al}_{1.5}$. (b) Temperature dependence of the integral intensity of NPD patterns at low angle range and macroscopic magnetization (ZFC) for $\mathrm{La}\left(\mathrm{Fe}_{11.5} \mathrm{Al}_{1.5}\right)$.

If there is a short-range ferromagnetic order (SFM), the long-range ordering $(0,0,0)$ magnetic peak should be converted to a diffuse peak at low-Q, which can be examined from the background intensity of NPD. To prove the existence of short-range FM order in $\mathrm{La}\left(\mathrm{Fe}_{11.5} \mathrm{Al}_{1.5}\right)$, the low angle neutron diffraction patterns at $H=0 \mathrm{~T}$ were analyzed. Clearly, the intensity of NPD patterns strongly depends on temperature, which decreases or increases monotonically with increasing 2 Theta (Figure S10a). The tendency of integral intensity is well consistent with the macroscopic magnetization (ZFC) (Figure S10b). The macroscopic magnetization comes from the FM order induced by magnetic field. Therefore, the analysis of low angle neutron diffraction can also qualitatively explain the existence of short-range $\mathrm{FM}$ order in $\mathrm{La}\left(\mathrm{Fe}_{11.5} \mathrm{Al}_{1.5}\right)$. 


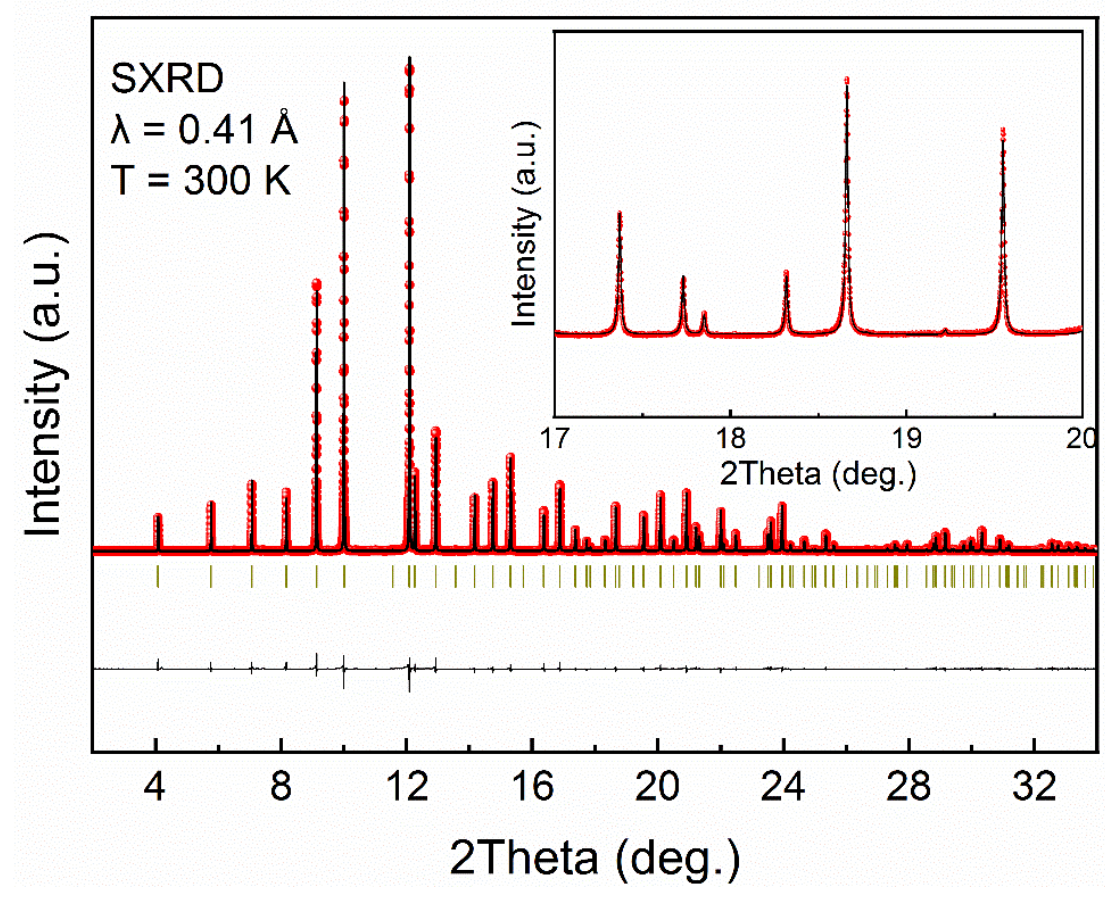

Figure S11. Structure refinement of the high-resolution synchrotron XRD (SXRD) patterns at room temperature of $\mathrm{La}\left(\mathrm{Fe}_{11.5} \mathrm{Al}_{1.5}\right)$.

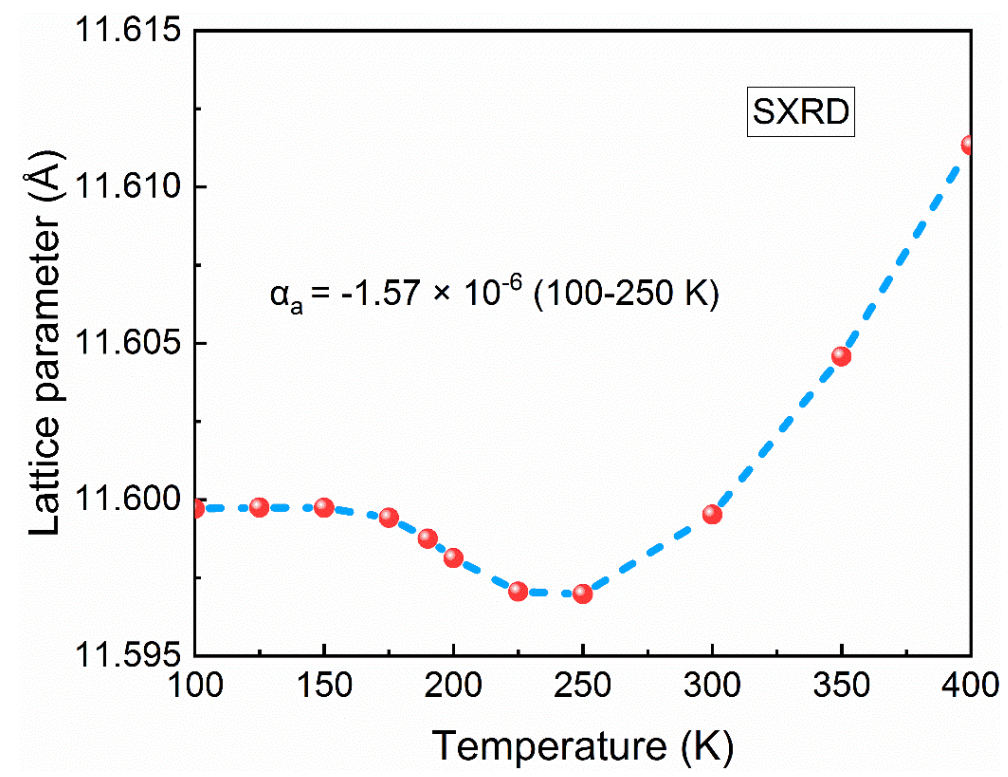

Figure S12. Temperature dependence of lattice parameter $a$ for $\mathrm{La}\left(\mathrm{Fe}_{11.5} \mathrm{Al}_{1.5}\right)$ at $\mathrm{H}=0$ T extracted from SXRD. 

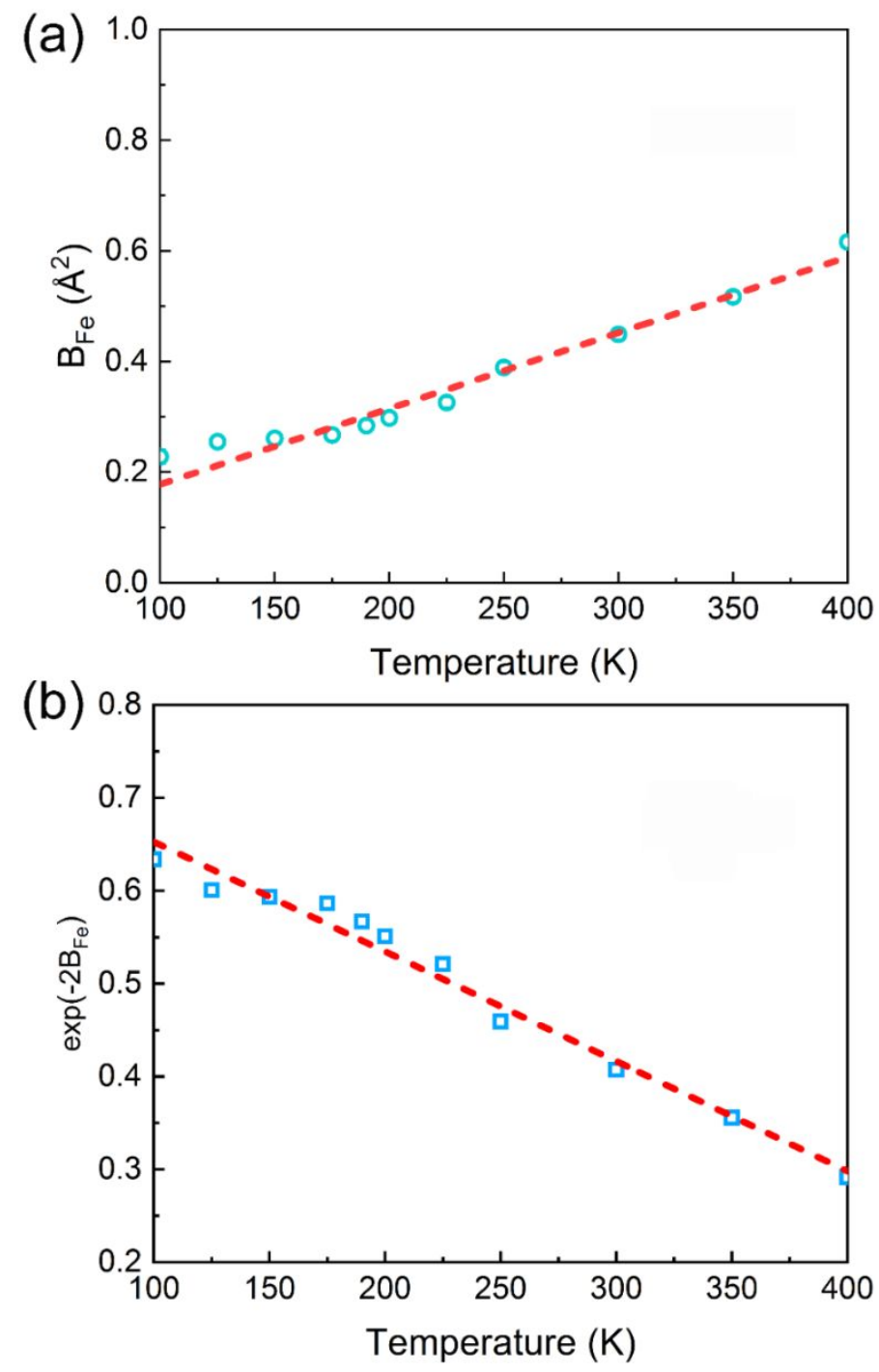

Figure S13. Temperature dependence of isotropic atomic displacement parameters of $\mathrm{Fe}\left(\mathrm{B}_{\mathrm{Fe}}\right)$ for $\mathrm{LaFe}_{11.5} \mathrm{Al}_{1.5}$ at $\mathrm{H}=0 \mathrm{~T}$ extracted from SXRD. (b) Temperature dependence of the attenuation coefficient of diffraction intensity $\left(\exp \left(-2 \mathrm{~B}_{\mathrm{Fe}}\right)\right)$ caused from thermal vibration.

It is known that with increasing temperature the amplitude of thermal vibration increases, so the diffraction intensity becomes weaker. To prove the linear decrease of the diffraction intensity influenced from phonon thermal vibration $\left(\mathrm{I}_{\text {Phonon }}\right)$, temperature dependence of isotropic atomic displacement parameters of $\mathrm{Fe}\left(\mathrm{B}_{\mathrm{Fe}}\right)$ for $\mathrm{LaFe}_{11.5} \mathrm{Al}_{1.5}$ 
at $\mathrm{H}=0 \mathrm{~T}$ is extracted from SXRD (Figure S13). As depicted in Figure S13a, the isotropic atomic displacement parameters of Fe increases linearly with the increase of temperature. According to the theory of Debye-Waller, $[1,2,3]$ the attenuation coefficient of diffraction intensity caused from thermal vibration was calculated by $\exp \left(-2 \mathrm{~B}_{\mathrm{Fe}}\right)$. Obviously, Figure S13b shows that temperature dependence of the exp($2 \mathrm{~B}_{\mathrm{Fe}}$ ) changes linearly (Figure $\mathrm{S} 13 \mathrm{~b}$ ), so the contribution of phonon thermal vibration ( $\left.\mathrm{I}_{\text {Phonon }}\right)$ to the integral intensity also decreases linearly with increasing temperature.

[1] Pecharsky, V.; Zavalij, P., Fundamentals of powder diffraction and structural characterization of materials. Springer Science \& Business Media, 2008.

[2] Vila, F. D.; Rehr, J.; Rossner, H.; Krappe, H., Theoretical x-ray absorption DebyeWaller factors. Phys. Rev. B 2007, 76, 014301.

[3] Maradudin, A.; Flinn, P., Anharmonic contributions to the Debye-Waller factor. Phys. Rev. 1963, 129, 2529. 